\title{
Prólogo \\ Las Ciencias Sociales y el desafío de la mercantilización del conocimiento
}

\author{
Antonio Elizalde Hevia \\ Email: antonio.elizalde@gmail.com
}

Cuando estábamos iniciando la redacción del prólogo del número 41 de Polis, hemos recibido desde REDALYC, una carta que señala lo siguiente:

"En referencia al blogpostScholar y Open Acces, en el que el bibliotecario estadounidense Jeffrey Beall trata de desacreditar la labor de los repositorios de acceso abierto, en específico las de SciELO y Redalyc, al compararlos con favelas, al tiempo que ensalza el trabajo de las editoriales comerciales, argumentando que estas últimas efectúan con mayor eficiencia la tarea de dar visibilidad a las revistas científicas, consideramos conveniente que tanto los editores de revistas de acceso abierto como las plataformas que apoyan este movimiento cierren filas en torno a estos ataques infundados y expresen su opinión al respecto en las redes sociales, así como en las páginas de sus publicaciones.

Es necesario alzar la voz en favor del acceso abierto, puesto que tanto los editores como aquellos que lo promueven han logrado cubrir las necesidades de información especializada de estudiantes, investigadores y tomadores de decisiones en materia de desarrollo científico y tecnológico. Esto es cierto, aunque los defensores de las editoriales comerciales no quieran verlo.”

En relación a esta carta, Leonardo Montenegro, editor de la revista Tabula Rasa ha comentado lo siguiente:

“Apoyo totalmente la protesta en contra de estos ataques contra los repositorios de acceso abierto, que son además un ataque a las revistas que están allí. Pero fuera de un ataque de un señor Beall, que pocos conocemos, lo preocupante es la actitud y las acciones de entidades como Colciencias (la institución para el fomento de la investigación y el desarrollo científico del gobierno colombiano), que sigue insistiendo en desconocer la labor de Scielo y de Redalyc, y que pretende que las revistas indexadas con gran reconocimiento (clase A) sean sólo aquellas que estén en bases privadas como ISI o Scopus. Colciencias pretende reconocer solamente a estas editoriales comerciales que están detrás de estos repositorios, avalando de esta forma la venta del conocimiento y que sólo acceda a él quien pueda pagar, mientras desconoce los alcances del open acces y la libre circulación del conocimiento. 
Por otra parte, las universidades y los profesores siguen este camino, en su interés en ganar "reconocimiento" unas y otros. Que en términos reales se ve traducido en entradas económicas. Sin embargo, a través del acceso abierto también se gana un gran reconocimiento, pero en un mundo controlado por la empresa privada angloeuropea del conocimiento, el arrodillamiento que impone la academia norteamericana hace que se busque el reconocimiento de ésta sin importar el resto del mundo ni de los aportes que se pueden hacer a él."

Enrique Zamorano, editor de Theoria, respondiendo a la carta de REDALYC señala a su vez: "Coincido con lo expresado y también aprovecho de manifestar mi rechazo al sistema que administra el conocimiento científico en nuestros países, que en lo sustantivo atiende el concepto neoliberal de mercantilizar el conocimiento científico, con los resultados que tenemos a la vista. En la editorial de nuestra revista he escrito cuáles son las ideas del directorio de la misma y en este escrito van reflejados los criterios que a nuestro juicio y el mío propio deberían primar a la hora de darle el valor al conocimiento creado. No soy el primero que lo expresa...’El conocimiento tiene valor per se y no según la revista que lo publique.”

Y adjunta el editorial mencionado, de su autoría, titulado "Revistas universitarias y la parábola del salmón” en el cual se señala lo siguiente:

“La tendencia editorial global imperante, que también se ha implementado en nuestro país con éxito en la mayoría de nuestras universidades, sitúa a nuestra revista, así como a tantas otras, en un plano de absoluta desigualdad, obligándoselas a competir en un mercado editorial que induce a investigadores de esas mismas universidades a publicar los resultados de sus hallazgos en revistas de categorías ISI preferiblemente y por lo cual muchas instituciones otorgan incentivos a los académicos que lo hacen.

A esta exigencia subyace también una imposición a las propias universidades que son capturadas por el mercado del conocimiento, controlado por editoriales extranjeras, impactando diversas esferas de la vida académica, desde mecanismos de evaluación académicos, que valoran mayormente este tipo de publicaciones, hasta los mismos sistemas de jerarquización que privilegian avances de jerarquía sustentados en revistas de esta categoría preferentemente. Con ello, se obliga a académicos/investigadores a difundir sus hallazgos, producto de su investigación, hacia aquellas publicaciones indexadas en base de datos ISI, como si el conocimiento no tuviese valor per se, sino dependiendo de la revista en que éste se publique.

Esto último, prácticamente no ocurre con revistas de las propias universidades las cuales no premian por publicar en sus propias revistas o, si lo hacen, es con una diferencia tan abismante que prácticamente se hace poco atractivo económicamente tal "negocio" y consecuentemente el número de trabajos recibidos en éstas se ha reducido dramáticamente a lo largo de los años. Es la alegoría del salmón y su superviven- 
cia a contracorriente, aplicada a la temática de la productividad científico-humanista.

La paradoja del sistema es que la mayoría de las revistas ISI no son de acceso abierto (OA), de tal forma que, en circunstancias que la investigación es financiada con fondos públicos, en nuestro caso dinero de todos chilenos, a los propios autores no les es dado acceder libremente a sus propios trabajos si la institución en la que trabaja no ha pagado suscripción para poder acceder a esta información, es decir: "pay per view" o "pague para ver”, que promueve el mercado de la información científica.

Es evidente que el modelo actual de difusión de la información científica, que nació en el siglo XVII, debe ser repensado como modelo de gestión o, si el lector lo desea, “como modelo de negocio” si aceptamos el lucro en el "mercado del conocimiento". A estas alturas del desarrollo de las sociedades en que ya la revolución industrial es cosa del pasado y la sociedad ha avanzado hacia la sociedad de la información, no es posible que información científica que la ciencia genera como sistema sea rehén de pagos y que la información emergida de procesos de investigación, largos y laboriosos, quede prisionera de "proveedores" que fijan elevadas tasas para acceder a sus bases de datos y consecuentemente sólo las instituciones poderosas tienen la posibilidad de pagar esos elevados costos.

Algunos estudios recientes (Houghton, Rasmussen, Sheehan, Openheim, Morris, Creaser, Greewood, Summers, Gourlay, 2009; Friend\&Swan, 2010) han identificado y cuantificado los costos y beneficios de tres modelos de publicación: vía suscripción, OA y de autoarchivo en repositorios. Ambos estudios concluyen que un OA a la ciencia mejoraría los rendimientos de la investigación, generando beneficios netos de largo plazo. Estos estudios ponen de manifiesto además que los beneficios emergen de un uso más eficiente de los recursos, así como de una mayor validez en las gestiones de las universidades en el ejercicio de sus tareas de investigación. Es indudable que este ahorro redundaría en efectos positivos para la propia comunidad científica de la organización, así como de sus bibliotecas.

La ciencia es un ejemplo por excelencia de colaboración creativa, no exento de las imperfecciones propias de un sistema construido por el ser humano. La enorme presión encima del científico de producir, léase publicar, ha tenido como una consecuencia no deseada un incremento en los fraudes, plagios y retractaciones (Fanelli, 2009). Es esperable que si los sistemas de evaluación académica se centran en cuantificar la productividad que a su vez es controlada de manera estricta por los comités en los órganos centrales de ciencia y tecnología para mantener subsidios o postular a ellos, los investigadores se ven a su vez presionados por adecuarse a un ranking, publicando hallazgos o resultados preliminares como definitivos.”

En una de las notas incluidas en un artículo del actual Lente de Aproximación se señala que: "Se le ha otorgado en España el Premio Prín- 
cipe de Asturias a SaskiaSassen. Un fragmento del comentario aparecido en la prensa española (Diario El País, 14 junio 2013) a propósito de esta importante intelectual dice lo siguiente: "La tercera enseñanza de SaskiaSassen nos lleva a la futura quiebra de nuestro sistema académico-universitario. Una de las científicas más importantes de nuestra época no ha conseguido ningún sexenio, ninguna acreditación, frente a los criterios de nuestras agencias de evaluación, que anteponen siempre el mismo criterio: tres publicaciones JCR (Journal Citation Reports) en los últimos cinco años. Sassen no tiene ni una, sino que ha publicado libros e informes, fruto de proyectos de investigación de verdad y referencias fundamentales para académicos comprometidos, ha publicado numerosos artículos en medios de gran difusión, etc., pero se ha resistido a la práctica de inflar su currículum con artículos estandarizados sin interés ni lectores, más allá de círculos de amigos de citación mutua. Estamos entregando nuestra calidad científica a Thompson Reuters (la empresa gestora de los JCRs) igual que la calificación de nuestras economías a Fitch, Moody's y Standard \&Poor's. La estandarización de nuestra enseñanza universitaria y de nuestra producción científica nos llevará a universidades sin debates, investigaciones sin compromiso y un sistema académico sin pensamiento. El tan merecido premio para SaskiaSassen nos deja, por lo tanto, un sabor agridulce porque puede representar un galardón para una representante de una estirpe en proceso de extinción.”

La información arriba provista nos permite destacar el meollo de la discusión que hemos querido abrir mediante la consulta realizada a un destacado y representativo colectivo de cientistas sociales latinoamericanos a quienes invitamos a realizar un esfuerzo colectivo para dibujar el escenario que se abre a nuestro continente y el papel que en éste deben jugar las ciencias sociales, convocándolos a escribir en torno a las siguientes preguntas: ¿Cuáles son los principales desafíos que enfrentarán las Ciencias Sociales en nuestro continente? ¿Cuáles son las principales preguntas que deberemos hacernos para contribuir al futuro de la democracia, de la paz y de la sustentabilidad en nuestras sociedades?

Nos sentimos profundamente satisfechos por la respuesta obtenida a esta convocatoria colectiva, aunque cerrada, realizada por primera vez en nuestra década y media de existencia, pues hemos recibido un conjunto de aportes de enorme calidad, que nos permiten proveernos de un horizonte en función del cual encaminar nuestros esfuerzos editoriales, que a la vez recogen muchas de las preocupaciones en torno a las cuales hemos estado contribuyendo, tanto con la reflexión teórica así como con los resultados de investigaciones que han sido publicados en nuestras páginas.

Como ya lo esbozamos antes, el meollo de la problemática que confrontamos dice relación con la confrontación con un modelo de sociedad en el cual lo económico termina siendo, aunque discursivamente se lo niegue, el principal determinante de lo realmente existente. Ello porque todos, sin excepción, hemos ido dejándonos llevar por el sistema (establishment) por diversas razones, comodidad, seguridad, tedio, interés, beneficios varios, 
entre muchas otras posibles de enumerar, de modo tal que hoy, nos encontramos virtualmente expropiados de nuestra condición ciudadana, en su potencial de ejercicio de una soberanía plena.

Incluso, muchos de quienes se consideran parte de la gran masa de “indignados potenciales" y reivindican actuaciones o posturas extra o asistémicas, son incapaces de tomar conciencia como casi la mayor parte de las diversas dimensiones constitutivas de su existencia cotidiana, están absolutamente funcionalizadas por el sistema.

Es ese el contexto en el cual se sitúa este número 41 que abre nuestro Lente de Aproximación con una contribución de Alberto Acosta quien en su artículo titulado Las ciencias sociales en el laberinto de la economía sostiene que esta disciplina ocupa un lugar imperial entre las ciencias sociales pero que paradójicamente busca desligarse de estas para aproximarse a las ciencias exactas y naturales, ya que exacerba su pretensión de -al igual que ellas-ser exactas y medibles, pero sobre todo neutrales, no obstante debatirse en un laberinto de ser una ciencia permanentemente en ciernes. Asumiendo los retos propios de la complejidad del mundo y los actuales retos para la Humanidad, la pregunta que se plantea en estas líneas es sobre el tipo de ciencias sociales que habría que construir para atender la reproducción de la vida y agrega nuevas preguntas a las de la convocatoria: ¿cómo afrontan las ciencias sociales los grandes problemas de la Humanidad y si proponen soluciones relevantes y adecuadas?, ¿han entendido las ciencias sociales que requieren una ética de vida, no simplemente una ética instrumental?, ¿serán capaces las ciencias sociales de reinventarse para asumir los retos propuestos, para comprometerse con los problemas a partir de entenderlos en su verdadera profundidad y densidad?, ¿serán las ciencias sociales un factor para construir democráticamente una sociedad democrática?, ¿conseguirán las ciencias sociales emanciparse de sus orígenes coloniales y de las ataduras que les impone el capitalismo?, ¿podrán las ciencias sociales ser actores de una gran minga global que permita impulsar el reencantamiento del mundo?

A continuación Héctor Alimonda en su artículo titulado Provocaciones sobre el tema "Extractivismo y Desarrollo" cuestiona la capacidad de los modelos exportadores de bienes naturales primarios para promover el desarrollo en nuestro continente, revisando el largo debate teórico que el pensamiento crítico ha realizado al respecto, y planteando la necesidad de superar el modelo extractivista, desconstruyendo las ideas establecidas respecto a sus beneficios.

Sigue un aporte de David Barkin titulado Las Ciencias Sociales en América Latina: ¡Una gran herencia a vencer! en el cual sostiene que las nuevas ciencias sociales han comenzado a reconocer la deuda que tienen con las comunidades que están forjando alternativas frente a los modelos dominantes del mercado mundial, con sus paradigmas de equilibrio y de crecimiento sostenido. Es así como los propios miembros de estas comunidades se están incorporando como participantes, elaborando nuevas teo- 
rías y fortaleciendo sus estrategias para forjar nuevas sociedades y proteger sus ecosistemas. De allí que para la comprensión de la construcción y la reconstrucción de las sociedades en proceso, las ciencias sociales tendrán que aprender de los propios constructores incorporando lecciones de las múltiples cosmovisiones que están revalorándose y de los enfoques sociales y políticos que plantean diferentes sociedades y sistemas productivos para obtener una mejor vida en equilibrio con sus ecosistemas.

Continua una contribución que se titula Las ciencias sociales ante el desafío de la integración social intercultural entre todos los pueblos de la tierra: Fenomenología, Hermenéutica y Praxeología, cuyo autorIván Canales realiza una reflexión crítica sobre la epistemología de las ciencias sociales actuales, y de su potencial categorial para pensar sistemáticamente una integración social intercultural, radicalmente plural, y socio-éticamente sustentable, es decir, en condiciones de un dialogo global, participativo en libertad y justicia. Afirma que debe tratarse "de construir una unidad cosmopolita, que coordine y norme la integración social de lo radicalmente plural, como un diálogo sin exclusiones (todos son legítimos interlocutores) y en condiciones de libertad y justicia.”

El aporte que Gian Carlo Delgado hace lleva por título Coproducción de conocimiento, fractura metabólica y transiciones hacia territorialidades socio-ecológicas justas y resilientes, y se hace desde la perspectiva del metabolismo social, o de la modalidad y dimensión del uso de energía y materiales por parte de la sociedad, realizando una descripción panorámica de la crisis imperante en la modernidad tanto en sus dimensiones socioeconómica como ecológica. Destaca que dicha crisis es la resultante de relaciones sociales de producción específicas en un contexto biofísico dado, planteando la relevancia del conocimiento especialmente mediante la conformación de nuevas disciplinas híbridas y campos de conocimiento híbridos y la coproducción de conocimiento basada en un continuo diálogo de saberes entre los actores directa e indirectamente relacionados, tanto para el diagnóstico robusto, como para la búsqueda consensuada de rutas de transición que apunten hacia territorialidades diferentes orientadas hacia a la construcción de esquemas genuinamente postcapitalistas enfocados en el bien común.

José Maurício Domingues contribuye con un artículo titulado Proyecciones de la teoría sociológica en América Latina: descripción, análisis y diagnóstico de la modernidad en el cual examina sintéticamente los principales debates teóricos más recientes sobre América Latina buscando así delinear los retos y desafíos fundamentales que la presente situación plantea a las ciencias sociales. Aborda primeramente las teorías de la “colonialidad del poder” y las teorías “descoloniales”; discutiendo luego algunas teorías sobre temas y áreas más específicos, buscando dar cuenta de los déficits teóricos que caracterizan el escenario contemporáneo. A partir de ese análisis sugiere algunas líneas de desarrollo teórico posibles para la sociología, con énfasis en la modernidad global y los “conceptostendencia”, ausentes desde hace algún tiempo de la teorización latino-ame- 
ricana y termina convocando a retomar la tarea de elaboración teórica que en el pasado emprendió la sociología latinoamericana, disputando a los científicos del norte, tareas intelectuales de carácter universalizante.

Una contribución titulada Desafíos para pensar desde la vida en las ciencias sociales nos ofrece María Luisa Eschenhagen,quien intenta develar la ceguera de las ciencias sociales frente a las problemáticas ambientales del mundo, problemáticas que aparecen fehacientes e innegables en la actualidad, mediante el análisis de varios textos que se dedican explícitamente a reflexionar sobre los retos y desafíos de las ciencias sociales. Llama la atención sobre la debilidad de interpretación del contexto socioambiental y conceptual que se encuentra en los textos considerados al abordar el análisis de los problemas ambientales imperantes, innegables en todas las escalas (regional, nacional, internacional) y muchas veces con derivaciones en términos de conflictividad social (en aumento casi exponencial). Esta ceguera se evidencia por ejemplo en la relativa ausencia del tema ambiental en el momento de proponer desafíos/retos de las ciencias sociales, como consecuencia de unas bases epistémicas que impiden pensar desde la vida y comprender la complejidad ambiental. Propone tres insumos para superar esta ceguera cognitiva: la colonialidad/modernidad; la complejidad y el pensamiento ambiental para pensar desde la vida, así como el sumak kawsay y el budismo para aproximarse a comprender la complejidad ambiental.

Las Ciencias Sociales en América Latina: lo permanente y transitorio, preguntas y desafíos de ayer y hoy se titula el artículo aportado por Dimas Floriani. Buscando responder las preguntas acerca del rol de las ciencias sociales latinoamericanas realiza un balance histórico y epistemológico de las ciencias sociales desde mediados del siglo XX, sus distintos métodos y matrices teóricas. Presenta asi mismo otros temas emergentes y estrategias plurales basadas en alternativas metodológicas y nuevos compromisos éticos y políticos, y deja abiertas un conjunto de interrogantes respecto al quehacer científico en un momento histórico en que las ciencias dominantes son las tecnociencias, las cuales producen para el mercado y en que las otras ciencias son controladas por lógicas e intenciones corporativas, como aquella ciencia que realizada desde la competencia entre los pares y mediante mediciones y evaluaciones de la productividad de cada uno, afectanuestras concepciones de ciencia y las formas de cómo producirla junto a los actores de la ciencia y a los demás integrantes de la sociedad.

Roberto Follari contribuye con su artículo Las ciencias sociales en la encrucijada actual en el cual señala que las ciencias sociales son lentas para asumir temas relevantes tales comola seguridad, el narcotráfico, la cultura mediática, incluso el neopopulismo y los actuales gobiernos latinoamericanos. Estas son temáticas cuyo desarrollo teórico y empírico está muy por debajo de lo requerido. Eso aunque Wallersteinnos haya alertado acerca de los problemas epistemológicos que se derivan de tomar al Estado/ Nación como unidad de análisis de lo social, puesto queel reemplazo del sistema/mundo como objeto ocasiona severos problemas, como aquellos 
que se han hecho manifiesto en las limitaciones para advertir la razón de los fracasos del socialismo en sus realizaciones históricas concretas. Sin embargo, la superación de esos problemas aparece menos clara en Wallerstein que en su diagnóstico, puesto que sus propuestas como la de la interdisciplina, resultan en ese caso poco fundadas y muy cercanas al sentido común, perdiendo inclusola arista crítico-ideológica de este autor que trabaja dentro del marxismo.

Con su artículo La recomposición de la triple vocación de la ciencia social en América Latina contribuye Manuel Antonio Garretón,señalando que las ciencias sociales se caracterizaron por el manejo de la tensión entre la pretensión científica y la dimensión intelectual crítica, buscando un cierto diagnóstico-imagen de la sociedad que permitiera su transformación. Sus tres grandes vocaciones, la científica, la crítica y la profesional estuvieron indisolublemente ligadas. Examina la actual disociación de estas dimensiones y discute tres desafíos que se abren, la transdisciplinariedad, el horizonte del concepto límite y la convergencia de las diversas voces de las ciencias sociales en América Latina.Concluye que las ciencias sociales en América Latina han tenido, a pesar de su fuerte pretensión de cientificidad, una tensión constituyente con un componente normativo, que ha orientado la acción social hacia la transformación social, en sus más diversas variantes, y que los grandes déficits en la construcción de nuestras sociedades en cuanto comunidades socio-económicas, políticas y culturales, están detrás de otra visión que tiene una expresión más antropológica y cultural que sociológica o política, donde la nación étnica fue avasallada por la nación cívica ya que la realidad colonial no ha sido nunca superada por estas sociedades. Por tanto el énfasis estará puesto en una visión de las fragmentaciones, los desgarros y la búsqueda de sujetos que expresan dimensiones de género, territoriales, étnicas, culturales, y de sociedad civil siempre oprimidos, y más cercana a la problemática de las modernidades múltiples que de los modelos de modernización.

\section{Retos para la Investigación en Ciencias Sociales en América Lati-} na en la temática de la Participación Social se titula el aporte de Mariada Gloria Gohn. Centra su análisis en las investigaciones temáticas respecto a la participación social de las personas en las acciones de grupo, grupos sociales organizados y movimientos sociales, planteando interrogantes tales como: ¿Cuáles son las principales líneas de investigación elaboradasal respecto por parte de investigadores de América Latina? ¿Cuáles son los métodos se han utilizado? ¿Qué soportes teóricos y metodológicos dan forma a los enfoques sobre los movimientos sociales? ¿A qué desafíos se han enfrentado los investigadores? ¿Qué retos se presentan para el futuro? Concluye que se tiene hoy en día, elementos de diversas teorías sobre los movimientos sociales y una gran colección de relatos sobre acontecimientos históricos donde participaron movimientos sociales, pero continua el desafío de "construir categorías teóricas para pensar acerca de los detalles de nuestra realidad, categorías que reflejen el movimiento real de esta realidad y capturen sus significados. Desafío inscrito en la necesidad de descolonización del conocimiento y del ser, pues muchas categorías usadas fue- 
ron construidas en círculos académicos que excluyen o minimizan los sujetos de las acciones y movimientos del Sur y se basan en la concepción de que sólo hay una manera de producir episteme o conocimiento para comprender el mundo.

Martín Hopenhayn nos aporta con Romper el tedio en busca de nuevos relatos: una interpelación a las ciencias sociales, una provocadora reflexión respecto a cómo la ritualización de las ciencias sociales en el mundo académico impone una dinámica de producción de conocimientos de creciente especialización y rigidez. Lo cual hace muy difícil crear nuevos relatos emancipatorios quenos proporcionen horizontes de sentido que permitan inscribir las acciones de actores políticos y sociales en estrategias de profundización de la democracia política, mayor igualdad social y realización de derechos civiles, sociales y culturales, promoción de políticas de responsabilidad ambiental y de vocación ecológica, empoderamiento de las comunidades, visibilización de los excluidos o los silenciados, promoción de derechos de las minorías, defensa de la paz y el respeto a la diferencia. Paradójicamente en espacios ubicados fuera de la academia, en el mundo de las redes y de las organizaciones de muy variada índole, se genera una gran cantidad de conocimiento social el cual al estar liberado del ritualismo academicista posee una gran potencialidad para concurrir en nuevos relatos movilizadores en torno a un imaginario global de derechos civiles, políticos, sociales, culturales y de solidaridad intergeneracional.

El desafío ético del respeto a las muchas verdades. Universidad, ciencia y otros saberes es el título que lleva la contribución de Francisca Márquez, quien afirma que la historia de las ciencias sociales en Latinoamérica indica que no habrá una virtuosa relación entre ciencia y sociedad en nuestro continente, si no se asume y revisa el complejo entramado de las estructuras sociales, de los poderes y saberes que subyacen a nuestras culturas. Señala que hoy parece indispensable insistir en la necesidad de explicitar las intenciones y los procedimientos que se ponen en práctica en las investigaciones sociales pues hoy la "autoridad científica" no se sostiene ni legítima en términos epistémicos y axiológicos si no se amarra a una verdad compartida, polifónica y enraizada en un perspectivismo. En este aspecto, los resultados de la investigación y el conocimiento científico pertenecen a todos, por ende los cientistas sociales son responsables pública y políticamente del conocimiento generado. Para articular el quehacer de los intelectuales e investigadores a las interrogantes de nuestras sociedades, el desafío es no sólo comprender los problemas que las estructuras sociales y campos de intereses no plantean.Sino también, los saberes otros, con los que la ciencia debe aprender a dialogar. El desafío para las ciencias sociales es, mediante un ejercicio reflexivo y polifónico, contribuir a develar las estructuras profundas de este mundo social, así como los mecanismos que tienden a asegurar, a menudo de manera violenta, su reproducción o transformación.

Carlos Walter Porto-Gonçalves en su artículo Por la Vida, la Dignidad y el Territorio: un nuevo léxico teórico político desde las luchas socia- 
les en Latinoamérica/AbyaYala/ Quilombola reflexiona sobre las interrogantes planteadas mediante el desarrollo un breve análisis de nuestra formación social / nuestras formaciones sociales relevando los desafíos que enfrentan las Ciencias Sociales, recupera los aportes del pensamientoacción crítico de Fals Borda; de los teóricos de la Descolonización; de la Ecología Política y la relación sociedad naturaleza; las propuestas de Estado Territorial; los análisis del Colonialismo Interno; y los aportes respecto a la Plurinacionalidad y la Interculturalidad que nos hacen los proponentes del Buen Vivir. Señala que la lucha por la Vida, la Dignidad y Territorio en que varios de los movimientos sociales identificados en el artículo están empeñados indican que la vida no se puede pensar,como en la tradición científica eurocéntrica hegemónica, fuera de la naturaleza.Que la dignidad es un reclamo por el respeto a su condición de otro ser digno, negado por el colonialismo de la modernidad que quería evangelizar, civilizar y luego desarrollarlo de acuerdo a sus diferentes momentos. Que hay que colocar en la agenda teórica y política, el respeto a la dignidad, el derecho a la diferencia que indica la diversidad biológica, donde inspiró creativamente, para afirmar sus culturas. Insinuar, además del universalismo, la pluriversalidad, en varias versiones de lo que puede ser en común. Sostiene también que en la medida que la cultura no es algo abstracto las condiciones materiales son necesarias para los horizontes de sentido en la vida, por eso el territorio es una categoría que reúne a la naturaleza y la cultura a través de las relaciones de poder en las condiciones materiales de vida. Por lo tanto, hay que desnaturalizar el concepto de territorio hasta ahora "base natural del estado". Concluye que abrir un nuevo léxico teórico-político es la tarea principal para las ciencias sociales hasta ahora marcadas por el eurocentrismo.

Continua esta sección de la revista con un sugerente aporte hecho por Adrian Scribano titulado Comienzo del Siglo XXI y Ciencias Sociales: Un rompecabezas posible, en el cual propone "jugar" con la idea de una mesa/superficie y cuatro piezas, y tomar el siguiente camino de ensamble: 1 ) identificar los rasgos sobresalientes de los procesos de estructuración social en tanto superficie de "juego"; 2) seleccionar tres componentes de las estructuras de las sensibilidades que conforman una pieza recortada al talle de la "lógica del desecho", "las políticas de la perversión” y "la banalización del bien”; 3) apartar en la composición de la figura, un esbozo de lo que implican el "saber tocar" y el "subsiadiano" (tensión entre ciudadano y consumidor que va cobrando la forma de subsiadano $=$ receptor de subsidios); 4) esquematizar los "retos" a nivel de la metodología, la teoría y la epistemología de las formas señaladas, en su rol de componentes claves del "ensamblado"; y 5) finalmente "armar" el rompecabezas re-marcando "lo necesario de seguir rechazando”. Concluye afirmando que “ni las prácticas intersticiales, ni las interdicciones colectivas, ni las experiencias de afirmación por si solas son suficientes para un acto inaugural de autonomía, tendremos que esforzar la sutileza de la observación para captar las nuevas situaciones donde se gesten topologías del rechazo a partir de la tensión mobesiana entre las tres."

Concluye el Lente de Aproximación con Pensar la sociedad: temas, 
problemas, retos para las ciencias sociales, colaboración en la cual Ximena Valdés realiza un rápido recorrido a la historia de cómo se fueron constituyendo las ciencias sociales y humanidades en nuestro sur del continente, revisa los cambios en las instituciones que las cobijaron, los temas y problemas que se plantearon, la relación entre producción de conocimientos cambio social, modernización, cultura, medio ambiente a lo largo de las últimas décadas. Plantea finalmente algunas de las dudas que merecen los nuevos formatos estandarizados de medición de resultados en la producción de conocimientos a los que ha adscrito nuestro país y sus instituciones científicas y universidades. Concluye que más allá de los temas y problemas estudiados, muchas de las preguntas que dieron su sentido a las ciencias sociales permanecen en un área de incertidumbre en una sociedad cada vez más compleja y diversa que reclama transformaciones.

El número incluye también dos interesantes aportes en su sección Cartografías para el futuro, el primero es de Federico Aguilera Klink quien realiza una interesante relectura de Smith y Marx para reflexionar críticamente sobre los derroteros actuales de la ciencia económica y desconstruirla noción de naturaleza humana con que trabaja la economía académica neoclásica o convencional y enseñada habitualmente como ciencia económica, constatando que tiene muy poco que ver con la esencia real de la naturaleza humana, tal y como vamos conociendo cada vez mejor.

El segundo de Omar Felipe Giraldo lleva a cabo una discusión epistemológica, sobre las condiciones de imbricación de la agroecología a la reproducción de los entramados vitales. Toma como base algunos conceptos del paradigma de la complejidad y presenta una reflexión sobre el tema técnico de la agroecología de base campesina en comparación con su contraparte industrial, y las características propias demandadas para una habitación humana que quiera integrarse al proceso constitutivo del orden natural.

Se completa este número de Polis con la sección Propuestas y avances de investigación, la cual incluye un total de once artículos, para finalizar la actual edición con el apartado Comentarios y reseñas de libros en donde se incluyen tres textos. 